\title{
Cost-benefit analysis of flood mitigation measures: a case study employing high-performance hydraulic and damage modelling
}

\author{
Daniela Molinari ${ }^{1}$ (D) Susanna Dazzi ${ }^{2}$ - Edoardo Gattai ${ }^{1} \cdot$ Guido Minucci $^{3}$. \\ Giulia Pesaro $^{3} \cdot$ Alessio Radice $^{1} \cdot$ Renato Vacondio ${ }^{2}$
}

Received: 24 September 2020 / Accepted: 21 May 2021 / Published online: 4 June 2021

(C) The Author(s) 2021

\begin{abstract}
This paper shows a detailed, advanced procedure to implement cost-benefit analyses (CBAs) in order to assess the effectiveness of flood mitigation measures. The town of Lodi (North of Italy) has been selected as a case study for the research work, as it was hit by a large flood in 2002 for which several data are available. In order to compute the benefits, in terms of avoided damage with the mitigation measure in place, micro-scale damage models developed within the Flood-IMPAT + project were used. The great amount of input data for such models comes from results of a two-dimensional river modelling, for what concern the hazard parameters, and from open-source database, to evaluate the vulnerability and the exposure of the hit area. The research highlights that technological-advanced, high-performance hydraulic models allow taking into account a variety of hazard scenarios, with reasonable computational time, supporting the proper accounting of the probabilistic nature of risk in CBAs. Nonetheless, such high-resolution tools support the implementation of micro-scale damage assessment models, which can provide information on the distribution of benefits in the investigated area, increasing the effectiveness of CBAs for policy making.
\end{abstract}

Keywords Flood risk $\cdot$ Cost-benefit analysis $\cdot$ River modelling $\cdot$ Flood damage $\cdot$ Urban flooding

\section{Introduction}

Riverine floods are natural phenomena that affect many people living in floodplain areas and cause serious damage to the built environment, urban services and natural ecosystem. In this regard, the EU "Floods Directive" (Directive 2007/60/EC) was established in 2007, requiring Member States to establish flood risk management plans (FRMPs),

Daniela Molinari

daniela.molinari@polimi.it

1 Dept. of Civil and Environmental Engineering, Politecnico di Milano, Milan, Italy

2 Dept. of Engineering and Architecture, University of Parma, Parma, Italy

3 Dept. of Architecture and Urban Studies, Politecnico di Milano, Milan, Italy 
in order to reduce the potential adverse consequences of flooding. In the largest Italian basin, one of the key players in the implementation of the Floods Directive is the Po River District Authority that has picked several APSFRs (Area with Potential Significant Flood Risk) within the catchments as the areas where flood analysis is a priority.

This paper considers one of these areas and shows part of the results of the research project Flood-IMPAT + (an Integrated Meso and micro-scale Procedure to Assess Territorial flood risk), undertaken by Politecnico di Milano in collaboration with the Po River District Authority and the partnership of several other stakeholders, in support of the implementation of the Floods Directive in Italy. In particular, the paper presents the cost-benefit analysis (CBA) of the mitigation measures built in the town of Lodi (North of Italy) after the last catastrophic flood occurred in 2002. Contrary to other CBA studies, the objective of this work was not related to the identification of the best mitigation strategy for the investigated area but to the choice of reliable, robust and informative tools to be used as the basis of any CBA by the Po River District Authority, for the development of FRMPs. In detail, the ex-post analysis of the implemented mitigation measures was conducted with high-performance hydraulic and damage modelling tools, with the objective of understanding potentialities and limitations of such an object-level, detailed approach.

CBA can be defined as a systematic procedure to compare the potential benefits of a given project (or activity) to the costs of employed resources, using money as unit of measure. Accordingly, it can be considered as an analytical tool which provides an overview of economic advantages or disadvantages in decision-making procedures (EC 2014). CBA has been used in projects for disaster risk reduction by different governments, international financial institutions, donors and NGOs since the middle-last decades of the twentieth century, and becomes more frequent in the last twenty years because of the recent context of austerity across many countries which calls for specific consideration of the economic efficiency of projects, including those related to disaster risk reduction (Mechler 2016). With specific reference to floods, CBA became mandatory for European Countries with the issuing of the Floods Directive, which explicitly asks for consideration of costs and benefits of any flood risk management measure. In fact, by permitting the comparison between today's clear mitigation costs and future uncertain benefits (i.e. risk reduction), CBA is an effective tool to support policy makers in choosing among several risk mitigation alternatives and to obtain consensus on the expenditure on public money in time of peace (Pesaro et al. 2018).

Nevertheless, recent international reviews show that CBA's ability to influence decision-making in disaster risk reduction is limited or even declining (Shreve and Kelman 2014; Mechler 2016; IEG 2010). This can be due to the different shortcomings of common practice for CBA in disaster risk reduction, which are well identified in Mechler (2016) and briefly reported below.

A first big issue is related to the limited capability of properly representing disaster risk. Disaster risk is a function of hazard, exposure and vulnerability in the investigated area; it is equal to the expected damage in the area, due to the occurrence of disastrous events, over some specified time period (UNISRD 2019). Benefits of disaster risk reduction projects thus correspond to the avoided expected damage linked to the project that is to risk reduction. Disaster risk is probabilistic in nature; if this nature is not taken into proper account, benefits can be wrongly estimated. Reasons for not addressing probability in the correct way are different. On the one hand, risk assessments are usually based on a limited number of hazard (and consequently damage) scenarios, mainly because of high computational efforts required by hazard modelling; moreover, these scenarios usually do not include most catastrophic events, on which little information is available for reliable modelling. On 
the other hand, the dynamics of exposure and vulnerability is difficult to capture and to be accounted for, and then often neglected.

A second limit of present CBAs lies in current damage modelling capabilities. In theory, all benefits that can be expressed in monetary terms should be included in CBA. As a matter of fact, only benefits linked to direct damage and loss of life are considered, mainly because of limitations in modelling indirect damage (Merz et al. 2010; Meyer et al., 2013). Yet, even estimations of direct damage can be incomplete, as most of the available damage models focus on a limited number of exposed elements, typically only residential buildings. Last but not least, damage estimation is characterized by significant uncertainty, which increases when damage estimation tools are not available for the area under investigation and must be adapted/transferred from different contexts.

Third, evaluating the distribution of costs and benefits of disaster risk reduction is still a big challenge; this is particularly tricky for decision-makers whose choices are also based on the evaluation of who is benefitting and who is taking disadvantages from a specific decision. This point is strongly related to the scale at which the analysis is carried out; as the scale increases "it becomes less clear how the intervention produces costs and benefits, who benefits and who is disadvantaged, and what other external factors come in" (Gowdy 2007).

Eventually, a further limit of present CBAs lies in the capacity of considering indirect factors like externalities, disbenefits and opportunity costs (i.e. losing benefits due to being unable to use funds for other important objectives). This is again due to large difficulty in modelling such items, possibilities for their identification and modelling being further hindered if the analysis is performed at a large scale.

The analysis carried out in this paper is aimed at understanding whether hydraulic and damage models with high resolution and performance can help to overcome the abovediscussed criticalities, and at which cost. Hydraulic modelling and damage modelling are research disciplines per se, with their histories and achievements. The present manuscript does not aim at bringing innovation in these specific fields, for which more or less consolidated tools are used. By contrast, the innovation claimed by the manuscript lies in the integration of these activities towards a cost-benefit analysis of a flood mitigation measure. The paper is organized as follows: Sect. 2 describes the case study under investigation; Sect. 3 explains methods and data implemented in the CBA, while Sects. 4, 5 and 6 are devoted to the description of results; the latter are critically analysed in Sect. 7 with conclusions closing the paper.

\section{Study site, reference past event, protection works realized}

Lodi is an Italian town, located in the Lombardia region (northern Italy). The municipality covers an area of $41 \mathrm{~km}^{2}$, and the number of inhabitants is about 45,000 (ISTAT 2018) with a population density of 1,095 inhabitants $/ \mathrm{km}^{2}$. The town is crossed by the Adda river, one of the largest tributaries of the Po river, which is the longest stream of Italy (the catchments of the river Po comprehend most of northern Italy for around $71,000 \mathrm{~km}^{2}$, while the Adda's one extends for around $8,000 \mathrm{~km}^{2}$ ). The territory around the town is basically flat, as Lodi is located in the largest alluvial plan of Italy (the "pianura Padana", formed by the Po and its tributaries), and is disseminated with irrigation ditches communicating with the Adda river. Moreover, the urban development of Lodi has brought to the construction of 
neighbourhoods and industrial zones in flood-prone areas. As a result, Lodi is exposed to a significant flood risk and has been included in the APSFRs of the Po basin.

The worst recent flood of the Adda in Lodi occurred in November 2002. The flood resulted from a most critical combination of events for the lower part of the Adda, namely the simultaneous increase of the discharges from the Como lake, of which the Adda is emissary, and of the Brembo river, that is the largest tributary of the Adda upstream of Lodi. During the night between the 25th and 26th of November, the Adda reached the hydrometric height of $3.43 \mathrm{~m}$ above the reference level (68.28 m a.s.1.), corresponding to a discharge between 1,800 and $2,000 \mathrm{~m}^{3} / \mathrm{s}$. The return period of the peak flow rate has been estimated as ranging between 100 and 200 years. Large portions of the town were flooded, on both sides of the river, with water levels above $2 \mathrm{~m}$ in some neighbourhoods. Some areas were flooded by the irrigation ditches and canals that suffered from backwater from the Adda river. Backwater generated by two bridges located in the town of Lodi also negatively contributed to flooding the surroundings. About 500 people were evacuated and the total damage exceeded $14 \mathrm{M} €$ (data supplied by the Municipal and Regional authorities and elaborated within the Flood-IMPAT + project). The residential and the business sectors were the most affected, up to an amount of, respectively, 7.8 and 4.1 M€; the remaining part of damage was mostly related to public services and infrastructure, whereas the agricultural sector contributed for only about $2 \%$, in accordance with the urban nature of the town.

After the event of 2002, for the hydraulic safety of the town, several protective structures have been designed and built on both the left and right banks of the Adda river under the supervision of the Interregional Agency of the Po River (Agenzia Interregionale per il fiume Po-AIPO) and of the Regional Authority (Regione Lombardia). However, in this article, only the defences built on the hydraulic right have been considered in a cost-benefit analysis (CBA). These defences include trapezoidal soil embankments, reinforced concrete walls and drain gates on the ditches. Moreover, mobile barriers are to be mounted onto the walls before calamitous events by dedicated personnel, in order to increase the elevation of the protection structure. A map with the Adda river, the City of Lodi, the Como lake and the Brembo river is presented in Fig. 1, together with a map of the works performed in Lodi; overall, the mitigation measures extend for approximately $3,500 \mathrm{~m}$.

\section{Materials and methods}

\subsection{Cost-benefit analysis}

In order to quantify the economic advantage of the built mitigation measure, the benefit/ cost ratio (B/C) criterion has been adopted, because it seems the most intuitive tool thanks to its relative metric (benefits per costs). In fact, $\mathrm{B} / \mathrm{C}$ is frequently used in the context of disaster risk reduction and to communicate with decision-makers (Shreve and Kelman 2014).

$\mathrm{B} / \mathrm{C}$ is defined as the ratio between the benefits arisen from a mitigation measure and the overall cost of its construction. In the context of flood risk management, costs are defined as the amount of investments needed to make the mitigation measures fully operational and include those for the risk assessment analysis, construction and maintenance of the built infrastructures. Benefits are instead defined as the potential damages to exposed assets, avoided thanks to the realization of the measure; considered damages 

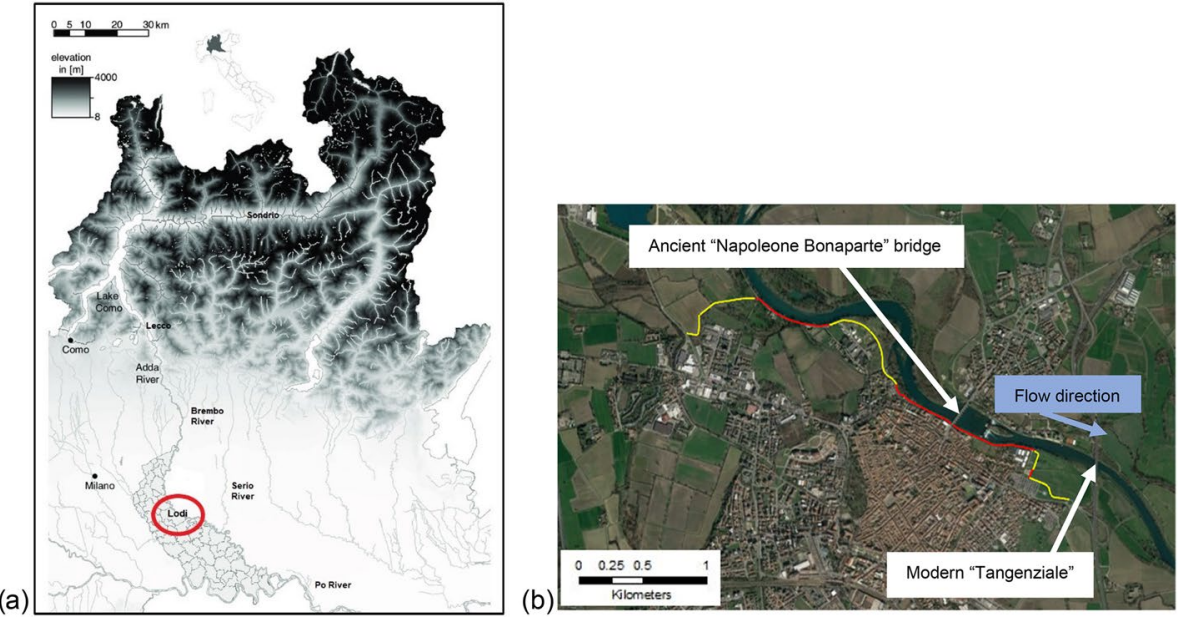

Fig. 1 a Context map with the Adda, Brembo, Serio and Po rivers, the Como lake, the city and province of Lodi; $\mathbf{b}$ track of the protection works built on the right of the Adda river at Lodi (flow is north-west to south-east), where yellow $=$ soil embankment and red $=$ concrete walls

must be quantifiable in monetary terms and include the physical damage to the built environment and the economic activities. Other indirect benefits include, for example, the potential economic growth, reduced costs for emergency management and reduced time of recovery.

In this study, B/C was calculated with the following equation:

$$
B / C=\frac{\int_{0}^{1} D_{1}(P) \mathrm{dP}-\int_{0}^{1} D_{2}(P) \mathrm{dP}}{\frac{C}{T}}
$$

where.

- $\mathrm{D}_{1}$ and $D_{2}(€)$ are the expected damages before and after the realization of the measure at stake;

- $P\left(\right.$ years $\left.^{-1}\right)$ is the exceedance probability of a flood event in one year (that is the inverse of the return period);

- $C(€)$ is the cost of the mitigation measure;

- $T$ (years) is the service life of the measure.

Equation (1) implicitly assumes a zero inflation. In fact, the total costs of the measure should be contextualized at the moment of the analysis and evaluated over the lifetime of the flood mitigation measure, considering a discount rate; the same should be done for future damages. However, considering that inflation has settled near zero in recent years, the assumption is considered reasonable for the present evaluation. Moreover, since a higher discount rate increases the preference of present benefactors and the burden onto future generations, very low or zero discount rate should be applied for environmental projects (Venton 2010). This is equal to assuming that protecting the environment for future generations have the same value as protecting the environment today (Shreve and Kelman 2014). 
In practice, computing the $\mathrm{B} / \mathrm{C}$ ratio requires, on the one hand, the assessment of the costs of the flood mitigation measure and, on the other hand, the quantification of the damages. The latter must be quantified with and without the mitigation measure in place. Risk is defined as the integral of the curve obtained by plotting the damage versus the exceedance probability of the flood; the difference between the integrals of the curves obtained for the conditions before and after the implementation of the flood mitigation measure represents the yearly benefits arisen from it. The integral of Eq. (1) thus allows considering all the probabilities (or return periods). If $\mathrm{B} / \mathrm{C}>1$, the benefits generated by the mitigation exceed the total costs, and therefore the structure represents a good investment for the society; the higher the benefit/cost ratio, the better the investment.

The estimation of $\mathrm{B} / \mathrm{C}$ implies then the following intermediate steps: (i) the estimation of the hazard intensity (e.g. the extension of the flooded area, the spatial distribution of the water depth and water velocity) for some discrete return periods chosen to discretize the damage-probability curve, with and without the mitigation measure, as the input to the damage assessment, (ii) the estimation of damages associated with each flood scenario, (iii) the risk assessment and (iv) the evaluation of costs. In the following subsections, methods and data implemented for hazard and damage modelling are described. As regard the hazard, it is obvious that a higher number of considered discrete scenarios (i.e. return periods) yields a more accurate representation of the damage-probability curves. In this study, thanks to the high performance of the adopted hydraulic model (see Sect. 3.2), four return periods were considered, equal to 50, 100, 200 and 500 years. These include some return periods typically used by the Po River District Authority for flood hazard and risk mapping, one of which (200 years) also is the design return period of the mitigation measure under investigation. With respect to damage, only direct damages to residential buildings and agricultural activities have been considered in this study, according to available damage models for the investigated context, developed within the Flood-IMPAT + project. This choice was led by the willingness to avoid the spatial transferability of foreign models, in absence of data for their validation.

\subsection{Hydrodynamic modelling: PARFLOOD}

Flood modelling has been performed via a two-dimensional (2D) model based on the Shallow Water Equations (SWE). In particular, we used the numerical code PARFLOOD (Vacondio et al. 2014, 2017). The code solves the 2D-SWE using a Finite Volume scheme, which allows simulating inundations over irregular bathymetries and with transcritical flows and wet/dry fronts (Vacondio et al. 2014). Moreover, the PARFLOOD model is implemented in CUDA/C + + programming language and exploits the computational capabilities of graphics processing unit (GPU) devices: thanks to the intrinsic parallelization of computations, runtimes are drastically reduced compared to serial codes (Vacondio et al. 2014), and high-resolution simulations of large domains are no longer hindered by their high computational cost. Vacondio et al. (2017) also introduced a new type of grid called Block-Uniform Quadtree (BUQ), which allows discretizing the domain with non-uniform resolution while maintaining the efficiency of the GPU. The adoption of BUQ grids is particularly useful for simulations of very large domains which locally require a high degree of detail, e.g. levee breaching, flood propagation in urban areas, etc. For a more detailed and comprehensive description of the model and its development, the reader is referred to Vacondio et al. (2014, 2017). The model has already been successfully applied to real test cases (see Vacondio et al. 2016; Dazzi et al. 2018, 2019, 2020; Ferrari et al. 2020), but this 
work represents the first exploitation of the results of PARFLOOD simulations to estimate the hazard parameters required by damage models. The model has been calibrated with reference to the flood of November 2002 and then used to generate hazard scenarios for the return periods considered in the study, in the two conditions with the mitigation structures not yet built and in place, respectively.

\subsection{Damage modelling for the residential sector: simple-INSYDE}

In order to compute the monetary damage to residential buildings, a simplified version of the INSYDE (IN-depth SYnthetic Model for Flood Damage Estimation, Dottori et al. 2016; Molinari \& Scorzini 2017) model has been adopted, called simple-INSYDE (Galliani et al. 2020). The latter is a synthetic micro-scale multi-variable model that presents the advantage of an explicit formulation and a user-friendly implementation, still implicitly maintaining the dependence of the original model from a large number of hazard (6) and vulnerability (18) parameters. The INSYDE model has been validated for the 2002 flood in Lodi by Molinari et al. (2020). Galliani et al. (2020) demonstrated that the use of simpleINSYDE leads to comparable results and does not decrease much the accuracy of the damage forecast compared to the full version of the model. In simple-INSYDE, the absolute damage $D_{\text {res }}(€)$ to a residential building (excluding its contents) is obtained summing up four damage components, using the following formulae:

$$
\begin{gathered}
D_{\text {res }}=\mathrm{RV}_{\text {basem }} \cdot A_{\text {basem }} \cdot d_{\text {basem }}+\mathrm{RV}_{\text {storey }} \cdot A \cdot\left[\sum_{i=1}^{n}\left(d_{\text {storey }_{i}}+d_{\text {floor }_{i}}\right)+d_{\text {boiler }}\right] \\
d_{\text {basement }}=f\left(A_{\text {basem }}\right) f(\mathrm{LM}, d u) \rightarrow\left\{\begin{array}{l}
f(\mathrm{BA})=0.02+\frac{0.35}{\sqrt{B A}} \\
f(\mathrm{LM}, d u)=1+0.3 \arctan (d u-36)
\end{array}\right. \\
d_{\text {storey }}=f(h) f(A) f(\mathrm{LM}, d u) f(\mathrm{BS}) f(\mathrm{FL}) f(q) \rightarrow\left\{\begin{array}{l}
f(h)=\left(0.17-0.02 h^{2}\right) \\
f(A)=\left(\begin{array}{l}
0.2+\frac{7}{\sqrt{A}} \\
0 .
\end{array}\right) \\
f(\mathrm{LM}, d u)=\left\{\begin{array}{l}
\text { if } \text { LM low, } 1+0.15 \cdot \arctan (d u-36) \\
f \text { LM high, } 0.8+0.2 \cdot \arctan (d u-36)
\end{array}\right. \\
f(\mathrm{BS})=\left\{\begin{array}{l}
1.35, \text { if } \text { BS masonry } \\
1, \text { else }
\end{array}\right. \\
f(\mathrm{FL})=\left\{\begin{array}{l}
1.35, \text { if } \text { FL high } \\
1, \text { else }
\end{array}\right. \\
f(q)=\left\{\begin{array}{l}
1.35, \text { if } q=1, \text { presence of pollutants } \\
1, \text { else }
\end{array}\right.
\end{array}\right.
\end{gathered}
$$




$$
\begin{gathered}
d_{\text {floor }}=f(h, \mathrm{FL})=\left\{\begin{array}{c}
0.04, \text { if } h>0 \text { and FL high } \\
0, \text { else }
\end{array}\right. \\
d_{\text {boiler }}=f\left(A_{\text {basem }}, h\right)=\left\{\begin{array}{c}
0.015, \text { if } A_{\text {basem }} \neq 0 \text { or } A_{\text {basem }}=0 \text { and } h>1.6 m \\
0, \text { else }
\end{array}\right.
\end{gathered}
$$

where.

- $d_{i}$ is the relative damage, considered as the ratio between the damage and the replacement cost of the exposed element in which the building is split (i.e. basement, storeys, pavements and boiler), obtained as a function of hazard parameters, i.e. water depth $(h)$, duration $(d u)$ and contaminant loads $(q)$, and vulnerability parameters, i.e. level of maintenance $(L M)$, building structure $(B S)$ and finishing level $(F L)$;

- $R V\left(€ / \mathrm{m}^{2}\right)$ is the replacement value of the building, obtained as function of different parameters, such as building type $(B T)$, building structure and finishing level;

- $A_{i}\left(\mathrm{~m}^{2}\right)$ is the footprint area of the flooded storey(s) or basement;

- $n$ is the number of flooded storeys.

\subsection{Damage modelling for the agricultural sector: AGRIDE-c}

Monetary damage to agriculture was estimated by means of the AGRIDE-c model for the Po plain (Molinari et al. 2019). The model furnishes, for different kinds of crops (namely, grain maize, wheat, barley and grassland), the damage suffered by an individual farmer. This damage is expressed in terms of percentage of the net margin the farmer would have if a flood did not occur. The relative damage is calculated as a function of hazard (i.e. water depth, duration and time of occurrence of the flood) and vulnerability (i.e. the tillage practice, and the strategy adopted by the farmers to alleviate flood damage) parameters. Figure 2 shows, as an example, the model for the estimation of flood damage to grain maize in case of minimum tillage.

\subsection{Used data}

The data used in the present study include:

- A Digital Terrain Model (DTM) of the area, with a resolution of $1 \mathrm{~m}$;

- Orto-photographs of the area;

- Cross sections of the Adda river, surveyed by the Po River District Authority between 2000 and 2002 during a study for hydraulic restoration of the Adda river;

- The hydrometric levels measured from July 1998 until June 2018 at the Napoleone Bonaparte bridge (see Fig. 1), obtained from the Environmental Monitoring Centre (ARPA) of Regione Lombardia;

- Peak discharges for reference return periods, according to the previous study by Rossetti et al. (2010);

- Images of the November 2002 flood event in Lodi from Civil Protection, Municipality and Police databases;

- The estimated extension of the flooded area during the event of November 2002 (Rossetti et al. 2010); 

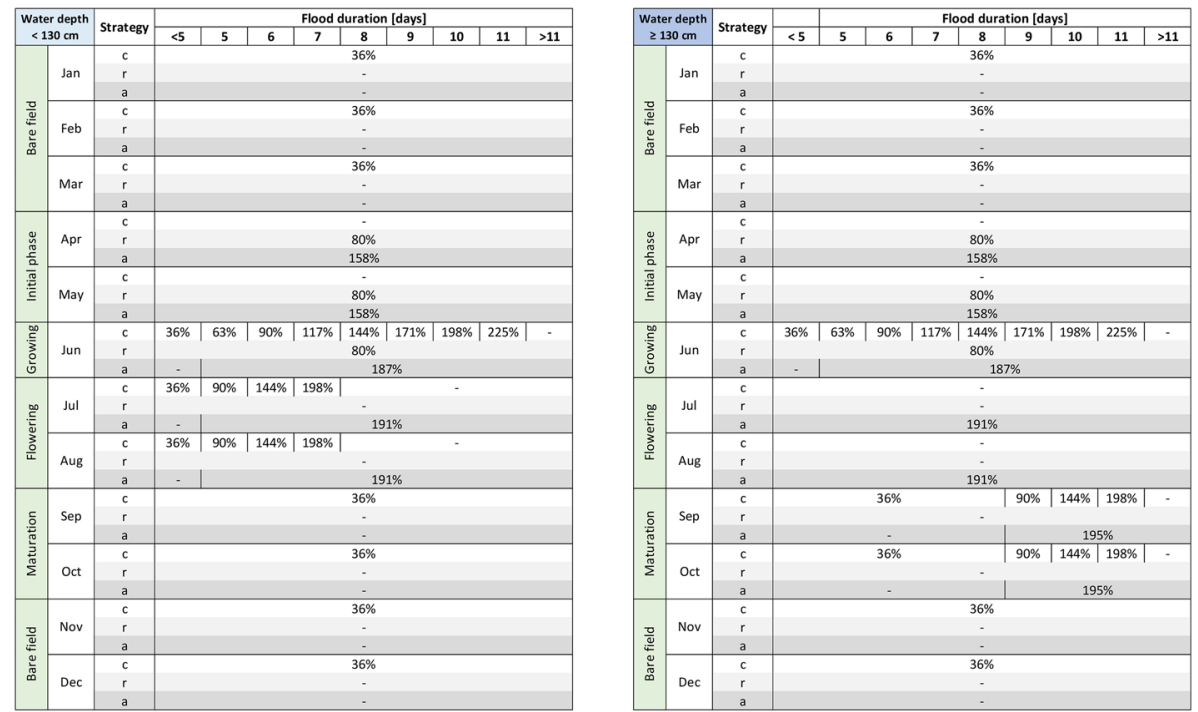

Fig. 2 Relative damage (i.e. percentage of the net margin of the farmer if a flood did not occur) to maize crops, in case of minimum tillage, for the different combinations of times of occurrence of the flood (i.e. month), flood intensities (i.e. water depth and flood duration) and damage alleviation strategies ("c" = continuation; "r" = reseeding; "a" = abandoning) (Molinari et al. 2019)

- Hydrometric levels at the Napoleone Bonaparte bridge during the event of November 2002 (Natale 2003);

- The estimated hydrograph of the November 2002 event (Natale 2003), with a duration of $120 \mathrm{~h}$ and a peak flow rate of $1,837 \mathrm{~m}^{3} / \mathrm{s}$;

- Values of the indoor water depth in 121 georeferenced control points (the red dots of Fig. 3) as reported in damage compensation forms compiled by citizens after the occurrence of the flood, and from reconstruction of photographs taken after the event;

- Geospatial vector file of the census zones in Lodi, including aggregated information on the level of maintenance, structure and construction typologies of residential buildings, taken from the National Statistical Office (ISTAT-Istituto Nazionale di Statistica) database;

Fig. 3 Points with information on inundation depth (red dots) and clusters used for the calibration of the hydrodynamic model (ellipses labelled with capital letters)

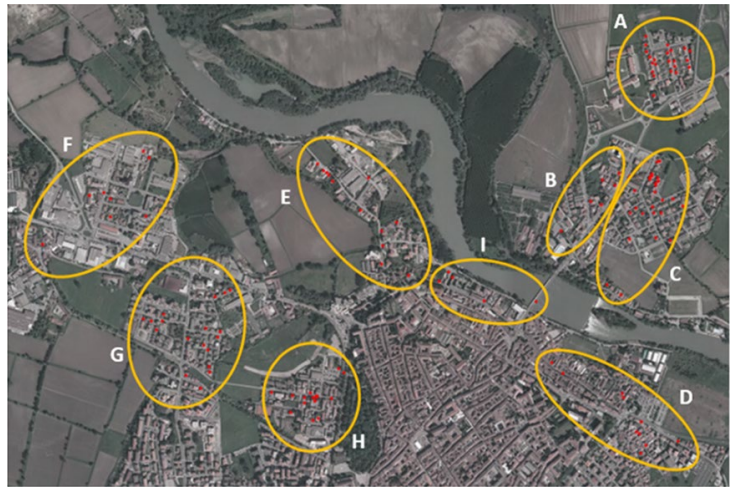


- Geospatial vector file of residential buildings in Lodi, taken from the Geoportal of the Province of Lodi, including local information on the footprint area and the number of storeys;

- Cadastral data of the buildings in Lodi, including local information on the presence of basement and the finishing level;

- Replacement value for residential buildings in Lodi, from CINEAS- CRESME - ANIA database (i.e. a shared database among the Consortium of Politecnico di Milano for insurers (CINEAS), the Centre for market and economic research on construction market (CRESME) and the Italian National Associations of Insurers (ANIA));

- Cadastral data of agricultural plots in Lodi, including information on the crop type, as included in the Agricultural Information System of Regione Lombardia (Sis.Co.);

- Geospatial vector file of agricultural plots in Lodi, including their extension, from the Agricultural Information System of Regione Lombardia (Sis.Co.).

\section{Results of inundation modelling}

\subsection{Set-up and Calibration of the hydrodynamic model}

As mentioned, a preliminary calibration of the hydrodynamic model was performed with reference to the 2002 flood event. The parameters used as a benchmark include: the boundary of the flooded area, measured hydrometric levels at the Napoleone Bonaparte bridge (see Fig. 1) and the values of water depth obtained from the damage compensation forms. These water depths were first converted into water elevations taking into account the elevation of the ground. Then, since the benchmark values were not uniformly distributed in space, they have been grouped into 9 clusters, named A to I as shown in Fig. 3; for each cluster, an average water surface elevation (WSE) has been computed. This procedure obviously carried some uncertainty related to the conversion from any indoor water depth into a water elevation; however, the uncertainty was reduced by the cluster-based averaging, which also damped the effect of possible outliers.

The modelled reach had a length of $17 \mathrm{~km}(3.5 \mathrm{~km}$ corresponding to the in-town portion of interest and an additional length to reduce the effect of a downstream boundary condition). The area of the computational domain was around $100 \mathrm{~km}^{2}$. Terrain data were obtained from the available high-resolution DTM, locally manipulated on the basis of onsite surveys. The domain was discretized using a non-uniform spatial resolution, equal to $2 \mathrm{~m}$ in the urban area (including the river), to $8 \mathrm{~m}$ along the rest of the river and to $16 \mathrm{~m}$ elsewhere (roughly 2.7 million cells overall).

In the urban areas, individual buildings were modelled as impervious blocks (see Fig. 4a), this being permitted by the fine computational grid. The roughness coefficients were calibrated to obtain a good match between simulations and observations. The best results were obtained with Manning coefficients of $0.033 \mathrm{~s} / \mathrm{m}^{1 / 3}$ for the main river channel and $0.015 \mathrm{~s} / \mathrm{m}^{1 / 3}$ and $0.06 \mathrm{~s} / \mathrm{m}^{1 / 3}$ for the urbanized areas and for those with brushes and forests, respectively. It is acknowledged that the heterogeneity of the study area could suggest considering additional roughness zones; however, the results presented below will show that a good model performance at control points was achieved even with this simplified Manning distribution. A hydrograph to be used as an upstream boundary condition (in a section about $5 \mathrm{~km}$ upstream of the Napoleone Bonaparte bridge) was expressed with the formula: 
(a)

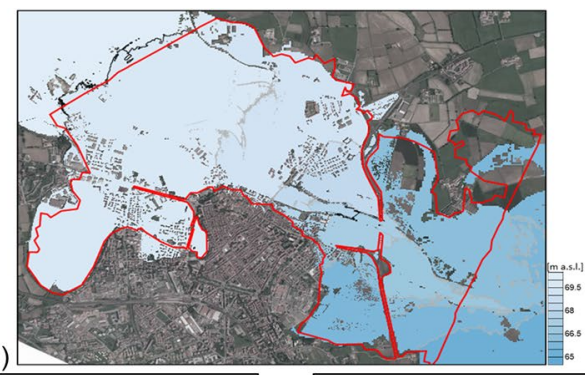

(b)
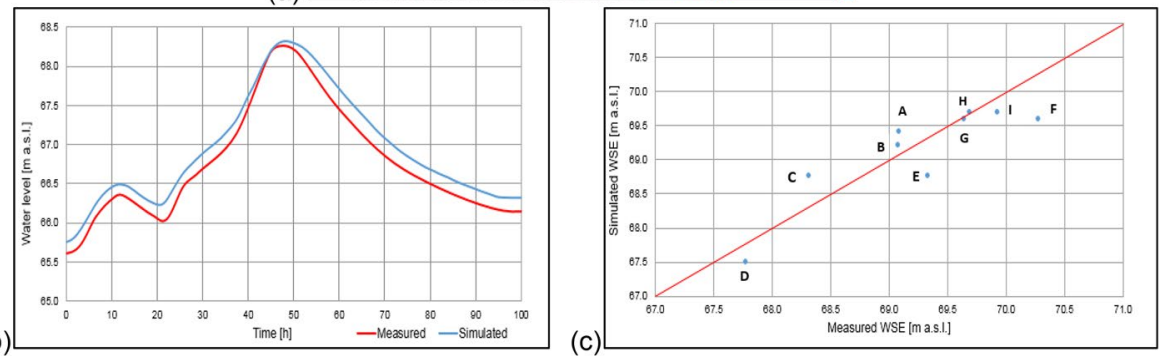

Fig. 4 With reference to the event of 2002: a flooded area returned by the hydrodynamic model, compared to that indicated by Rossetti et al. (2010) (in red); b measured and simulated water levels at the Napoleone Bonaparte bridge; $\mathbf{c}$ measured and simulated water elevations for the point clusters of Fig. 3

$$
Q=4.9521 * H^{3.2557}
$$

where $Q$ is the discharge $\left(\mathrm{m}^{3} / \mathrm{s}\right)$ and $H$ is the water depth $(\mathrm{m})$ at the section of the hydrometer just downstream of the Napoleone Bonaparte bridge. Flow hysteresis was neglected given the relatively short distance between the section of the upstream boundary condition and the bridge. The peak flow rate was $1,840 \mathrm{~m}^{3} / \mathrm{s}$. A stage-discharge relationship was used as a downstream boundary condition; the latter was placed at a bridge section and was sufficiently far from the town to avoid a significant influence on the water elevations in Lodi. The results obtained with the calibrated roughness are depicted in Fig. 4. The flooded area matches the observed perimeter quite well, with the exception of a slight overestimation on the West side of Lodi and a few missing areas downstream of the "Tangenziale" bridge (Fig. 1). The agreement with the water levels measured at the gauging station is also very good: the peak water elevation at the Napoleone Bonaparte bridge is captured with a $4 \mathrm{~cm}$ difference, and maximum difference along the event is $16 \mathrm{~cm}$. As regards the control points, the comparison between surveyed and simulated levels is quite satisfactory: the mean elevation difference for the clusters is $0.11 \mathrm{~cm}$, the mean absolute difference is $0.30 \mathrm{~cm}$, and the Nash-Sutcliffe Efficiency Index (NSE) is 0.74 .

\subsection{Flood scenarios for variable return period}

In order to create the flood hazard maps, necessary to estimate potential damages, synthetic hydrographs were determined for return periods of 50, 100, 200 and 500 years. The peak flow rates were retrieved from earlier determinations of the Po River District Authority, also reported by Rossetti et al. (2010): $Q_{50}=1,642 \mathrm{~m}^{3} / \mathrm{s} ; \mathrm{Q}_{100}=1,806 \mathrm{~m}^{3} / \mathrm{s}$; $\mathrm{Q}_{200}=1,971 \mathrm{~m}^{3} / \mathrm{s}$; and $\mathrm{Q}_{500}=2,187 \mathrm{~m}^{3} / \mathrm{s}$. Furthermore, synthetic discharge hydrographs 
(a)

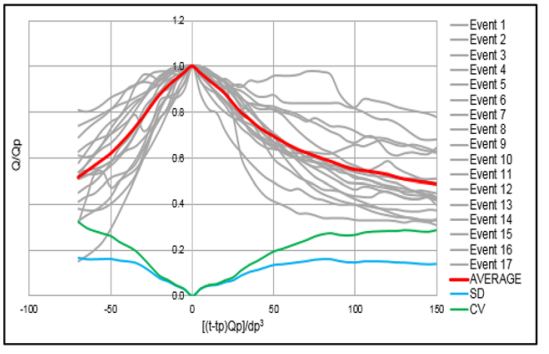

(b)

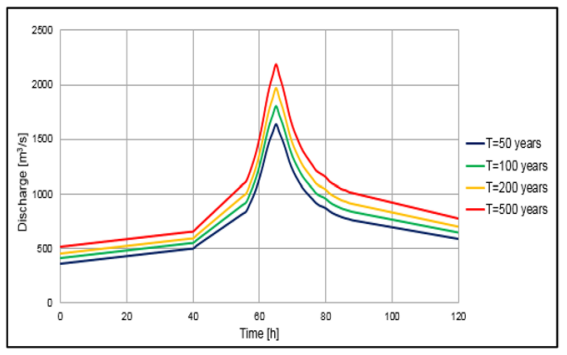

Fig. 5 a Dimensionless event hydrographs for the last 20 years, with mean, standard deviation and coefficient of variation; $\mathbf{b}$ synthetic hydrographs used as upstream boundary conditions for variable return period

(a)

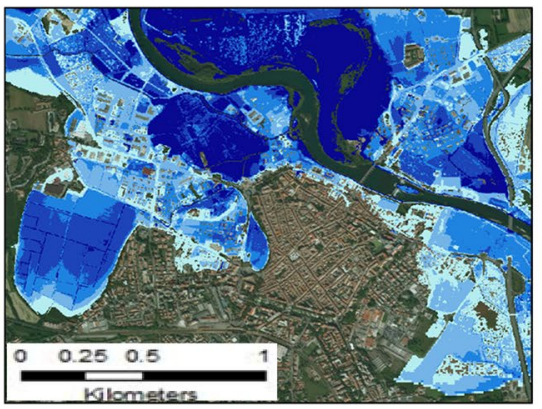

(b)

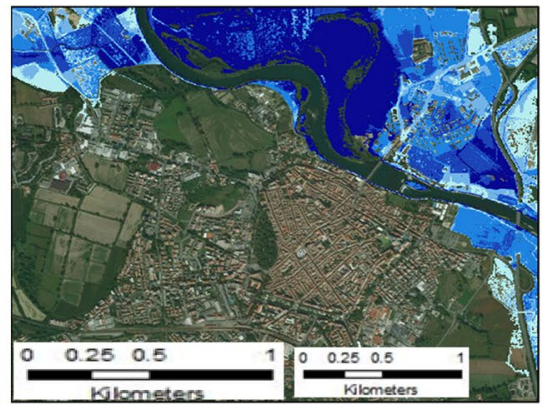

Fig. 6 Extracts of flood hazard maps (maximum water depth) for a return period of 200 years a without the mitigation structure and $\mathbf{b}$ after its construction

were determined by averaging the discharge time series for flood events with a peak flow rate exceeding $970 \mathrm{~m}^{3} / \mathrm{s}$ during the last 20 years of recordings at the Napoleone Bonaparte bridge gauging station (water elevations were converted into discharge using Eq. (7)). Figure 5(a) presents all these dimensionless hydrographs, where scaling factors are $t_{p}$ as the peak time, $Q_{p}$ as the peak flow rate and $H_{p}$ as the peak water depth. The plot also includes the mean dimensionless hydrograph, the standard deviation and the coefficient of variation of all the hydrographs. The different hydrographs obviously had variable shape, but the coefficient of variation of the discharge was less than $10 \%$ for $\left[\left(t-t_{p}\right) Q_{p}{ }^{3}\right] / H_{p}{ }^{3}$ varying between -25 and 30; the mean hydrograph thus seems a reasonable representation of a typical behaviour of the river. The dimensionless shape has then been used to create the synthetic hydrographs with assigned return period, based on the known values of the peak discharge, as shown in Fig. 5(b). Hydrodynamic simulations of the propagation of these synthetic hydrographs were carried out with the model parameters determined during the calibration.

For the scenarios without structural defences, both the flooded area and the depth values increase for higher return period. As an example, Fig. 6 shows the comparison between the maximum water depth maps without and with structural defences for the synthetic event with 200-year return period as a reference case (maps related to the other scenarios can be found in supplementary material). We focus on the water depth instead of the water velocity, because the latter assumed relatively low values as a result of the slope of the river Adda (less than $2 \%$ ) and of the floodplain context. Moreover, the water depth is the first 
hazard parameter required by existing models to calculate direct damages. Grid cells with water depth greater than $3.5 \mathrm{~m}$ were excluded from the representation, in order to reduce the range of displayed water depths (values in the river are up to $15 \mathrm{~m}$ ), thus maintaining a better resolution for the values in the city. This obviously implies that water depths are not depicted in the main river channel, that is well recognizable in the middle of the maps. It is evident from Fig. 6 that, with the addition of the mitigation structures, no flooded areas are detected on the hydraulic right for the return period of 200 years; indeed, the mitigation measures were designed to contain the 1/200 years' flood (including a safety freeboard). By contrast (as can been seen in the maps supplied in supplementary material), with the return period of 500 years a considerable area resulted flooded in the upstream portion of the domain due to the overflow of some elements of the structural defences (this being reasonable as the 500-year flow rate is larger than the design one). In general, the construction of the mitigation structures on the right side determines a slight increment of the levels on the left (from 3 to $10 \mathrm{~cm}$ ). These detailed inundation data were crucial to achieve an accurate damage assessment as described in the following.

\section{Results of damage assessment}

\subsection{Residential sector}

Applying simple-INSYDE requires each building in the flooded area to be characterized in terms of local hazard and vulnerability. To this aim, it was assumed that the water inside the buildings could be promptly pumped out and so would not persist for more than $24 \mathrm{~h}$. For the water depth outside a building, the maximum water depth on the building perimeter was used to determine the flood damages. The potential presence of pollutants in the water was finally considered as able to increase damages to the built environment.

The building vulnerability was evaluated as follows. Starting from the available information on the presence of basement, if a cellar was present, the basement area was assumed equal to the footprint area of the construction; otherwise, a zero value was attributed. For buildings with no information on the presence of a basement, we considered the presence of a cellar with an area equal to the footprint area of the building multiplied by the percentage of buildings with a basement (determined from the sample of the buildings for which data were available). In this we reached a complete assignment of the basement area for all the involved built environment and respecting a proportion of basement presence. For what concerns the level of maintenance (LM), a distinction between high and low value was made (as required by simple-INSYDE) starting from information contained in the ISTAT census file. In particular, for each census area, the total number of buildings with optimal and good state of conservation was determined, as well as that of the buildings with moderate and very bad level of maintenance. Then, a representative value of LM has been assigned to each census area based on the prevailing state. Such value was given to all buildings included in the census area. Similarly, for the building structure (BS), the representative value of each census area was defined according to this procedure: if the percentage of masonry structure was greater than other types, such as reinforced concrete and wood, a greater value of the parameter was assigned for all the buildings belonging to the considered census area; otherwise, a lower value was attributed.

The results of the implementation of simple-INSYDE to all investigated hazard scenarios show that, according to the design return period of the levee system (200 years), for the 
(a)

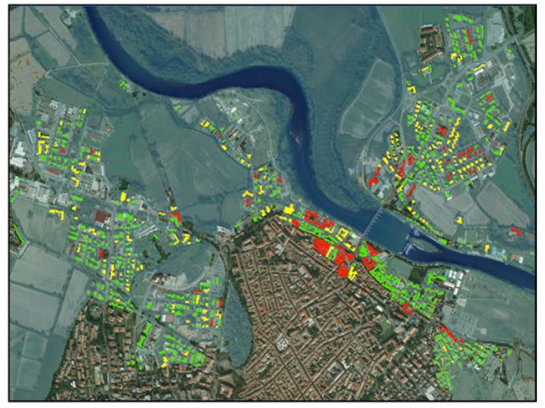

(b)

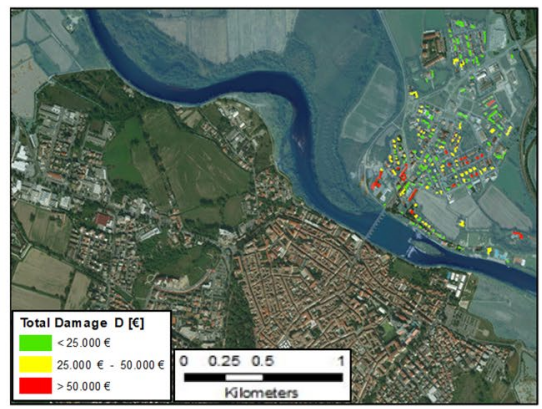

Fig. 7 Damage assessment to residential buildings a without the mitigation structure and $\mathbf{b}$ after its construction, for the return period of 200 years. The colour legend is the same for the two panels

Fig. 8 Relationship between the exceedance probability of an event and the expected damage to residential buildings, without and with structural measures

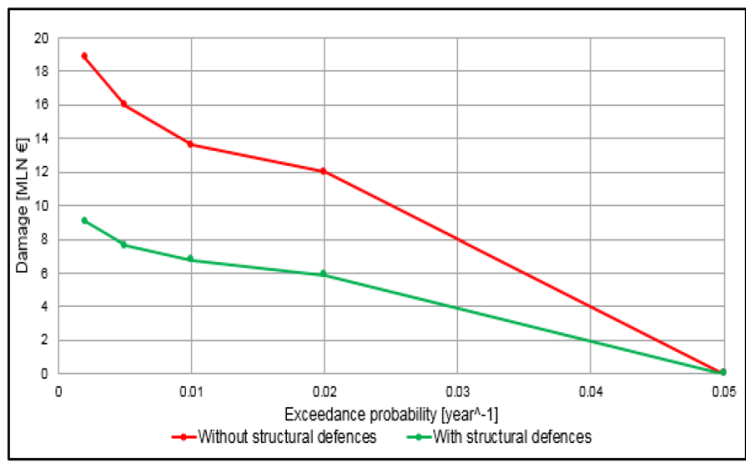

scenarios with 50, 100 and 200 years of return period, damages to residential buildings on the hydraulic right are completely avoided. On the contrary, for the 500-years scenario, the flood water overtopping the mitigation structures causes some damages to the residential area on the north-west side of the historical municipality. Figure 7 depicts an example of damage assessment for the return period of 200 years. Finally, Fig. 8 displays the estimated damage to residential buildings versus the exceedance probability of the flood, for all the investigated hazard scenarios; preliminary analyses showed that no residential buildings and only few agricultural plots are flooded for very frequent events (return period $\leq 20$ years), as also suggested by previous local studies (AdbPo 2003). Considering the low amount of damages coming from the agricultural sector we therefore assumed no quantifiable damage for 20 years of return period (see also Sect. 5.2). A linear trend has then been assumed between the estimated damages for the investigated scenarios; this is obviously a simplification, but it does not flaw the outcome of the study. The curves show similar trends of damage, with the only exception of the higher increment of damage from 100 to 200 years without structural defences. The latter is due to the fact that, without protection on the hydraulic right of the river, a considerable increase of the flooded area has been estimated for the scenario with 200 years with respect to the one for 100 years. On the contrary, with the addition of the structural defences, the smaller increment of damage is only due to an increase of the water depth in the flooded area. 


\subsection{Agricultural sector}

In order to implement the AGRIDE-c model, for each agricultural plot, information about the area occupied by the different crops considered by the model (already available from cadastral data) was combined with information on the hazard and on the vulnerability of the investigated area. The hazard parameters required by AGRIDE-c include: water depth, duration and time of occurrence of the flood. As regards the water depth, an average value has been computed, for each agricultural plot, by overlapping the hazard maps and the geospatial vector file of the agricultural plots. The computation of damages to agricultural sector has been performed assuming that the flood occurred in November. This choice derives from the analysis of the hydrometric levels in Lodi, from the second half of 1998 until June of 2018, showing that November is the month when high water stages in the river have been registered more frequently (2002 flood event included). Finally, as regards the permanence of water on the field, considering the crop types present in November and their life stages, it can be assumed that the duration of the flood does not influence the potential damage in this period of the year (see also Molinari et al. 2019). Indeed, grain maize and soy are absent and the damage is associated with the bare soil only. Wheat and barley are in the germination phase, and in case of flood, the damage is total even for very rapid floods, being the crops in the weakest stage of their life. Grassland is in the vegetative rest phase, and no damage is observed until the permanence of the water reaches more than 15 days, a very infrequent phenomenon in the area under investigation. Nonetheless, the impact of grassland on the total damage to agriculture is very low with respect to the other types of cultivations. With respect instead to vulnerability, AGRIDE-c requires to set the tillage practice and the alleviation strategy adopted by the farmer. In the perspective of assuming the most convenient setting for the farmers, the minimum tillage and the most economically convenient strategy, for the time and the crops investigated, have been, respectively, adopted, for all plots in Lodi.

Figure 9 depicts some sample results identifying the parcels with different levels of damage. Then, Fig. 10 displays the estimated damage to crops versus the exceedance probability of the flood, for the investigated hazard scenarios and considering again a damage of zero for 20-year return period and a linear trend between scenarios. The initial growing trend of the damage is due to the increase of the flooded area for different reference scenarios. Indeed, for return periods equal to 50 and 100 years a greater number of agriculture

(a)

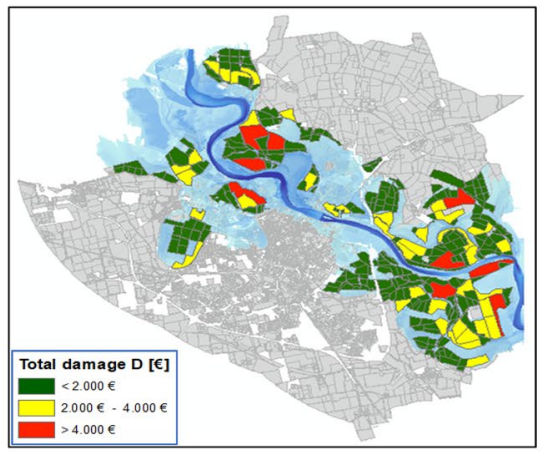

(b)

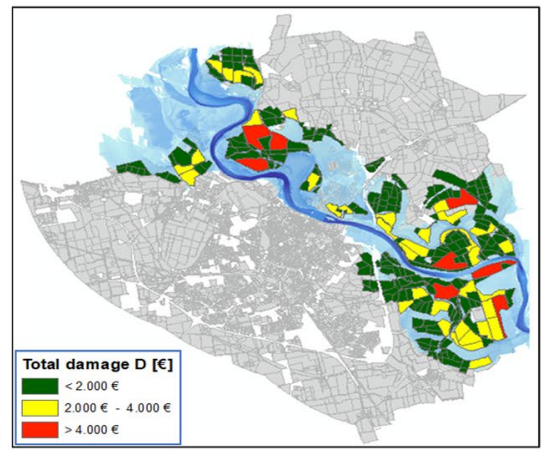

Fig. 9 Damage assessment to the agricultural sector $\mathbf{a}$ without the mitigation structure and $\mathbf{b}$ after its construction, for the return period of 200 years 
Fig. 10 Relationship between the exceedance probability of an event and the expected damage to the agricultural sector, without and with structural measures

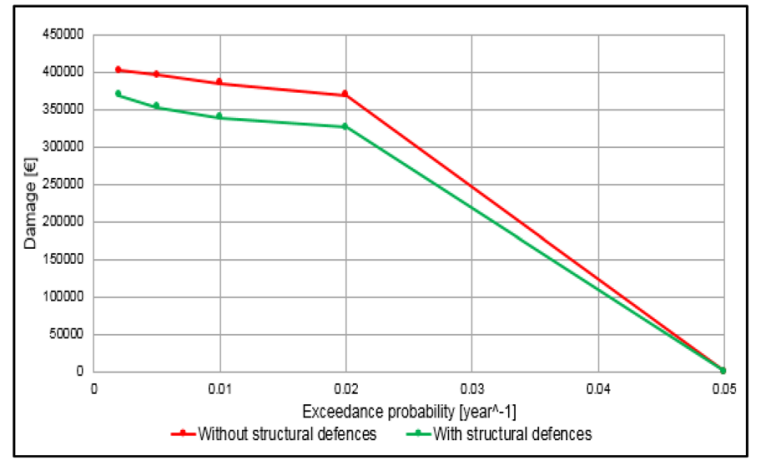

fields are hit by the flood. On the contrary, only a slight increase of the damage is observed from the 100-year scenario to the 200-year one due to a small increment of the flooded area. Increasing the severity of the event, namely the 500-year flood scenario, a wider flooded area is obtained but mainly in the urbanized zone nearby the historical part of the city. The latter causes an increment in the damage to residential buildings but not for the agricultural sector. The only increase in crop damages for the 500-year scenario is due to slightly higher water levels registered with respect to events with lower return period.

\section{Cost-benefit analysis}

The above results (Figs. 8 and 10) demonstrate that the construction of the mitigation structure reduces the expected damage. For the residential sector, for all the reference scenarios, the damage reduction due to the presence of the levees varies between 50 and 52\% (Table 1), in accordance with the fact that the structural defence protects only the right side of the river, while flood and damage modelling covers the whole urban area. For the agricultural sector, the estimated damage reductions with the flood protection in place vary between 11 and $13 \%$ for the events with return periods of 50,100 and 200 years. The percentage slightly decreases for the 500-year event, due to the additional embankment overflows which inundate an area on the North-East side of Lodi, which is mostly dedicated to

Table 1 Reduction of damage due to the mitigation structure for different return periods

\begin{tabular}{|c|c|c|c|c|c|}
\hline \multirow[t]{2}{*}{ Involved assets } & \multirow[t]{2}{*}{ Variable } & \multicolumn{4}{|l|}{ Scenarios } \\
\hline & & $\mathrm{T}=50 \mathrm{y}$ & $\mathrm{T}=100 \mathrm{y}$ & $\mathrm{T}=200 \mathrm{y}$ & $\mathrm{T}=500 \mathrm{y}$ \\
\hline \multirow[t]{3}{*}{ Residential buildings } & $\begin{array}{l}\text { Damage without structural defences } \\
{[\mathrm{M} €]}\end{array}$ & 12.00 & 13.58 & 15.98 & 18.80 \\
\hline & $\begin{array}{l}\text { Damage with structural defences } \\
{[\mathrm{M} €]}\end{array}$ & 5.89 & 6.76 & 7.63 & 9.06 \\
\hline & Damage reduction [\%] & 51.0 & 50.3 & 52.2 & 51.8 \\
\hline \multirow[t]{3}{*}{ Agricultural activities } & $\begin{array}{l}\text { Damage without structural defences } \\
{[\mathrm{M} €]}\end{array}$ & 0.37 & 0.38 & 0.40 & 0.40 \\
\hline & $\begin{array}{l}\text { Damage with structural defences } \\
{[\mathrm{M} €]}\end{array}$ & 0.33 & 0.34 & 0.35 & 0.37 \\
\hline & Damage reduction [\%] & 11.7 & 12.0 & 10.8 & 8.1 \\
\hline
\end{tabular}


agriculture. The percent reduction of flood damages is more or less constant for all the considered hazard scenarios, in accordance with the results of inundation modelling. In fact, Figs. 1 to 8 in supplementary material show that, contrary to what expected, the protection level offered by the levees on the right bank is high even for return periods exceeding the design one, such us most of the urban area on the right side of the river is no flooded also for such an extreme event. In accordance, the damage reduction level remains constant.

However, do these damage reductions compensate the cost for the construction of the defences? This is the question we will answer thanks to a CBA.

The yearly avoided damage to residential buildings is about $€ 223,300$, while that for the agricultural sector is around $€ 1,400$ (two orders of magnitude lower than the former). This is due, on the one hand, on the prevailing urban inclination of the investigated area and, on the other hand, to the fact that damage to agriculture is minimized in November because mostly of the cultivated crops are in the resting phase. Summing up the aforementioned figures, the final result is $€ 224,700$, representing the annual quantifiable benefit coming from the construction of the structural defences on the hydraulic right of the Adda river. The total cost of the intervention was about $€ 4,394,800$. Considering a lifetime of the structure of 100 years, the cost of the flood protections is $43,948 € /$ year. The annual expense for ordinary maintenance is $€ 31,700$, to which $18,000 € /$ year must be added for training courses of the personnel assigned to the assembly of the barriers onto the concrete walls. Therefore, the total cost per year is around $€ 93,648$. This corresponds to a $\mathrm{B} / \mathrm{C}$ ratio equal to 2.4 , meaning that the structural defences produce yearly benefits, in terms of avoided damages, that are 2.4 times the total yearly costs of the flood protections. Therefore, the conclusion of this analysis is that the mitigation structures pay back for the initial investment of their construction. However, it must be noted that only damage to the agricultural and the residential sectors was considered and no damages with return periods greater than 500 years have been computed; therefore, the final amount of potential avoided quantifiable damages could be underestimated, while $\mathrm{B} / \mathrm{C}$ values could be even higher. Moreover, the estimation of $\mathrm{B} / \mathrm{C}$ can be affected by the real functional duration of the structures that is unknown, especially regarding the reinforced concrete defence walls. In this regard, the functional duration of the flood protections for which yearly costs equal the estimated arisen yearly benefits $(\mathrm{B} / \mathrm{C}=1)$ has been computed as equal to 25 years. This means that the mitigation measure would continue to be effective for functional duration greater than 25 years. Finally, considering the scenario in which serious events occur frequently, as evidences from recent years show, and in the case that the flood protections do not suffer heavy consequences, the $\mathrm{B} / \mathrm{C}$ ratio would definitely grow.

\section{Discussion}

In this section, we discuss advantages and limitations of the methods used in this study, with particular reference to CBA shortcomings that were discussed in introduction.

The urban flood simulations were performed using an accurate and efficient two-dimensional, unsteady flow model and a high-resolution mesh. The model was calibrated using data for a major flood: we obtained a difference of $6 \mathrm{~cm}$ between the simulated water level and the observed one at the level gauge station mounted on the Napoleone Bonaparte bridge, and an average error of $14 \mathrm{~cm}$ with respect to more than 120 observed depth data in the flooded area. Treasuring the parameterization for the simulation of synthetic scenarios led to a reliable representation of the flood hazard in terms of spatially distributed values of 
water depth, velocity and duration. Technological advancement is crucial for this achievement, because computational time is always a major constraint for hydrodynamic modelling. In this sense, the use of a numerical solver at the forefront of hydraulic science for both accuracy and efficiency (such as PARFLOOD) is an asset, not only for improving the effectiveness of the calibration process (and thus for reducing model uncertainty), but also to foster the proper consideration of the probabilistic nature of risk into CBAs, as more hazard scenarios can be considered without tremendously increasing computational efforts. For example, the runtime of the calibration simulation is only $8 \mathrm{~h}$ (for $120 \mathrm{~h}$ of physical time) on a Nvidia K40 Tesla ${ }^{\circledR}$ GPU (physical/computational time ratio=15), despite the high mesh resolution $(2 \mathrm{~m}$ ) and the large number of computational cells (around 2.7 millions). Buildings were treated as impervious blocks, disregarding the indoor water storage. The interactions with the subsurface systems and with minor moving obstacles, such as cars, garbage bins and bus stops, were also neglected. The results are however sound because of the performed calibration.

The quantification of damages to residential buildings was carried out at the microscale (i.e. at the level of individual affected buildings), thanks to the high resolution of the hydrodynamic simulations. We used a simplified version of the INSYDE model. Water depths were taken from the hazard maps, while vulnerability and exposure values were obtained from data at the census level. Such a micro-scale approach supports a better definition of the distribution of benefits in the investigated area, increasing the information base for more effective CBAs for policy making; still, a more detailed survey and knowledge on vulnerability and exposure elements, at the level of individual buildings, would further improve the quality of the assessment and support the definition of possible risk mitigation interventions for the single construction. Indeed, knowledge of the spatial distribution of benefits at the time of intervention would have led to the comparison of alternative mitigation strategies, working at different spatial scales, like the construction of the levees versus the delocalization of urban areas mostly at risk or the improvement of most vulnerable buildings. In this work, however, benefits were evaluated only at the level of the whole municipality, according to the area of influence of the specific measure under investigation (i.e. the levee system).

As regards damage to agriculture, we only considered the occurrence of the flood in November. However, future researches should be focussed on a better evaluation of the effect of the distribution of damage across the year (depending on the time of occurrence of the flood and the corresponding vegetative stage of the plants) on the estimation of the yearly expected damage and, on turn, on risk. Given the importance of the time of the year, risk estimates should not be based only on annual probabilities, but also on seasonal probabilities; this would imply changing the present conceptualization of flood return periods (Molinari et al. 2019). Nonetheless, in this paper, only damage to crops has been considered, while future assessment should be extended to other damageable components of a farm (i.e. livestock, storage material, machineries), in order to supply more comprehensive damage estimation to be included in a CBA.

The lack of comprehensiveness of the damage assessment is a limitation of our assessment. Damage estimation was limited to direct damage to residential buildings and agriculture in order to implement models specifically calibrated in the context under investigation and to avoid the spatial transfer of foreign models. This could have compromised the reliability of damage estimation (Cammerer et al. 2013; Molinari et al. 2020), above all in absence of data for validation. Exhaustiveness of damage assessment is also limited here by the disregard of systemic and indirect damages like loss of property value because of the flood, damages due to business disruption, ripple effects and others. These items are 
difficult to be evaluated due to the complexity of phenomena and (inter)linkages leading to damage and the lack of standardized modelling tools (Merz et al. 2010; Meyer et al. 2013). To cover this gap, the collection and the share of ex-post damage data, in a unique and consistent manner, should be encouraged, leading to an improvement of damage models calibration and validation (Molinari et al. 2019). The creation of a common database (such as the European Union spatial data infrastructure, proposed by the EU INSPIRE Directive) containing the aforementioned elements, will ease the identification of required data and results.

However, in the absence of adequate damage models, neglected (avoided) damages can be considered by means of proxy variables (e.g. exposure reduction) within a more comprehensive multi-criteria analysis (MCA) of the project; this alternative approach would allow considering also intangible benefits like saving of life, cultural heritage, ecosystems, etc. The development of a full MCA is beyond the scope of this paper. However, in order to supply a more comprehensive appraisal of the benefits related to the mitigation measure under investigation, Table 2 shows the reduction of some damage proxy variables, within the flooded area and for the different return periods considered in the analysis, for some of the exposed items neglected in the damage assessment. In detail, the following proxy variables have been considered:

Table 2 Reduction of damage proxy variables due to the mitigation structure for different return periods

\begin{tabular}{|c|c|c|c|c|c|}
\hline \multirow[t]{2}{*}{ Involved assets } & \multirow[t]{2}{*}{ Variable } & \multicolumn{4}{|l|}{ Scenarios } \\
\hline & & $\mathrm{T}=50 \mathrm{y}$ & $\mathrm{T}=100 \mathrm{y}$ & $\mathrm{T}=200 \mathrm{y}$ & $\mathrm{T}=500 \mathrm{y}$ \\
\hline \multirow[t]{3}{*}{ Economic activities } & $\begin{array}{l}\text { Exposed value without structural } \\
\text { defences }[\mathrm{M} €]\end{array}$ & 120.79 & 128.12 & 197.58 & 293.89 \\
\hline & $\begin{array}{l}\text { Exposed value with structural defences } \\
{[\mathrm{M} €]}\end{array}$ & 62.61 & 62.61 & 63.35 & 69.40 \\
\hline & Exposed value reduction [\%] & 48.2 & 51.1 & 67.9 & 76.4 \\
\hline \multirow[t]{3}{*}{ Population } & $\begin{array}{l}\text { Exposed people without structural } \\
\text { defences [-] }\end{array}$ & 6439 & 6858 & 8399 & 9647 \\
\hline & $\begin{array}{l}\text { Exposed people with structural defence } \\
{[-]}\end{array}$ & 2524 & 2542 & 2547 & 3233 \\
\hline & Exposed people reduction [\%] & 60.8 & 62.9 & 69.7 & 66.5 \\
\hline \multirow[t]{3}{*}{ Roads } & $\begin{array}{l}\text { Exposed roads without structural } \\
\text { defences }[\mathrm{km}]\end{array}$ & 60.1 & 66.9 & 72.6 & 79.9 \\
\hline & $\begin{array}{l}\text { Exposed roads with structural defence } \\
{[\mathrm{km}]}\end{array}$ & 40.9 & 43.2 & 46.4 & 52.1 \\
\hline & Exposed roads reduction [\%] & 31.8 & 35.4 & 36.1 & 34.7 \\
\hline \multirow[t]{3}{*}{ Important facilities } & $\begin{array}{l}\text { Exposed items without structural } \\
\text { defences [-] }\end{array}$ & 46 & 51 & 58 & 65 \\
\hline & $\begin{array}{l}\text { Exposed items with structural defence } \\
{[-]}\end{array}$ & 23 & 25 & 27 & 29 \\
\hline & Exposed items reduction [\%] & 50.0 & 51.0 & 53.4 & 55.4 \\
\hline \multirow[t]{3}{*}{ Cultural heritage } & $\begin{array}{l}\text { Exposed items without structural } \\
\text { defences [-] }\end{array}$ & 24 & 28 & 32 & 37 \\
\hline & $\begin{array}{l}\text { Exposed items with structural defence } \\
{[-]}\end{array}$ & 13 & 15 & 16 & 18 \\
\hline & Exposed items reduction [\%] & 45.8 & 46.4 & $\mathbf{5 0 . 0}$ & 51.4 \\
\hline
\end{tabular}


- The economic value of the exposed businesses (i.e. the maximum potential damage), calculated on the bases of the net asset value;

- The exposed population, in terms of residents;

- Exposed roads, in terms of kilometres of roads within the flooded area;

- The number of exposed important facilities, including: commercial services (to which belong hotels, supermarkets and banks), health services, police stations, public services (schools, universities, research laboratories, courts), religious places and sport facilities;

- The number of exposed cultural goods, including: industrial architectures, residential architectures and services, religious structures, rural buildings and infrastructures.

Table 2 clearly shows that real benefits are higher than those calculated by means of the damage assessment (and this is especially true if also indirect damage would be considered), as significant reductions are expected for all proxy variables. However, their quantification in monetary terms, and then their inclusion in a CBA, is still challenging for the area under investigation.

Underestimation of benefits is also linked to the discretization of the damage-probability curve. In this work, no return periods greater than 500 years were considered. Therefore, the final amount of potential avoided quantifiable damages was likely underestimated, as a value of the $\mathrm{B} / \mathrm{C}$ ratio including extremely rare events. However, hydrological information for extremely rare events would be so poor that any result based on it would be unreliable.

In fact, literature strongly underlines that any CBA is affected by uncertainties, that potentially increase with the scale of the event, due to the presence of assumed values adopted in the analysis (Handmer 2003). These uncertainties also regard the estimation of costs and benefits, discount rates or externalities evaluation (IDEA 2014), making the outcome of a CBA highly sensitive to the assumptions one makes (Brouwer and van Ek 2004). This is obviously the case also of the analysis performed in this paper although, as previously discussed, certain expedients were taken in order to reduce uncertainty (e.g. the use of high-performance hydraulic modelling to enhance the calibration process, as well as the use of local damage models). A sensitivity analysis of the most critical and uncertain input parameters should always be carried out in order to critically interpret CBA results, so as to increase the usability of CBAs for decision-making. In this paper, given the robustness of the result $(B / C=2.4)$, a full sensitivity analysis was not carried out; indeed, the use of local calibrated models should guarantee that uncertainty in input parameters does not affect the positive evaluation of the mitigation measure. However, an analysis was made to appreciate how CBA results would change for plausible evolutions of hazard and exposure/ vulnerability conditions in the investigated area.

First, we evaluated changes in CBA outcome in the case flooding predominantly occurs in May rather than in November. This allows assessing the potential effects of a modification of the seasonal distribution of extreme events because of climate change, i.e. to better incorporate the probabilistic nature of risk. Climate change and urban development are key elements contributing to increased flood damage (Poelmans et al. 2011). Recent studies have shown different effects of climate change on flood risk (Löschner et al. 2017) and the Intergovernmental Panel on Climate Change claimed, with low confidence, that climate change has affected the frequency and magnitude of flooding (IPCC 2014). The choice of the month for the sensitivity analysis derives from the investigation of the hydrometric levels described above, identifying May as the second most hazardous month for hydraulic extremes. Considering inundations in May, 
damages to agricultural activities change because, in this period of the year, crops are in a different life stages with respect to the ones in November. In particular, the estimated benefits to agricultural sector rise to $€ 3,000$ /year, leading to a $\mathrm{B} / \mathrm{C}$ ratio of about 2.42 . This minor change in CBA results is due to the fact that estimated damages to the agricultural sector are two orders of magnitude lower than those for the residential buildings, as the Municipality of Lodi is mainly characterized by a urban environment. It is however worth noticing that, in this case, the result of the CBA is slightly greater than the one obtained for the flood in November. This is because the avoided damage to agricultural sector increased considering the crops life stage in May.

Second, sensitivity analysis can also be applied to assess the $\mathrm{B} / \mathrm{C}$ ratio of alternative (future) scenarios, supporting the inclusion of exposure and vulnerability dynamics into CBA. For example, the effect of local and regional development plans, in terms of future spatial patterns of exposure and vulnerability, can be investigated. In the case of Lodi, the local development plan does not include new growth areas in the floodplain; however, we considered the scenario linked to a "levee effect", in terms of a false sense of safety after the construction of the mitigation structures (Di Baldassarre et al. 2018). In this scenario, the construction of flood protections generates an economic growth of the protected area and this is accompanied by a lack of resilience from the population, in terms of bad memories of events that occurred in the past. Finally, the scenario involves new urbanization of flood-prone areas behind the defence walls and levees. To perform the analysis, a new potential urbanized area is assumed, located between present residential zones and few industrial sheds. The hypothesis is that this new area would be filled by other residential blocks, with similar characteristics to the surrounding ones. Moreover, a further sensitivity analysis has been performed, considering two different typologies of constructions, in terms of type of building structure, presence of basement and finishing levels. In fact, these three parameters, involved in the computation of direct damage to residential building, have a great influence in the final amount of potential damage. In particular, buildings made of bricks are more vulnerable than reinforced concrete and wood, the presence of basement implies the total flooding of it with the addition of the damage to the boiler, while high finishing levels lead to higher damages. Considering the two opposite conditions of construction parameters (which are representative of a resilient urbanization and not), the expected damage in case of levee overtopping ( $\mathrm{T}=500$ years) ranges from $3,700 €$ to $45,500 €$ for each new building, corresponding, respectively, to an additional damage with respect to the reference scenario between 1 MLN $€$ to 12.3 MLN $€$. The new residential buildings would be located in fields currently dedicated to agriculture sector. Therefore, the construction of the new residential area would bring to a reduction of the potential damage to agriculture in November of approximately 13,300 €. Considering the new damages to agriculture sector and the two opposite values of additional damage to residential building, the

Table 3 Updated B/C ratio for a "levee effect" scenario

\begin{tabular}{lll}
\hline Construction tipology & $\begin{array}{l}\text { Yearly benefits to residential buildings } \\
\text { (avoided damages) }\end{array}$ & B/C results \\
\hline Original urban configuration & $€ 224,700$ & 2.4 \\
Less resilient & $€ 222,000$ & 2.38 \\
More resilient & $€ 205,000$ & 2.2 \\
\hline
\end{tabular}


$\mathrm{B} / \mathrm{C}$ of the measure would decrease as shown in Table 3. However, the yearly benefits still exceed the costs of the structures, proving the effectiveness of the flood protections even in this aggravated scenario.

\section{Conclusions}

This paper presents the cost-benefit analysis (CBA) of the hydraulic defence built in the town of Lodi (North of Italy) after the last catastrophic flood occurred in 2002. The analysis, conducted with high-performance hydraulic and damage modelling tools, highlights that such an object-level, detailed approach can help overcome the known limitations of common CBAs for disaster risk reduction. First, technological-advanced, high-performance hydraulic models allow taking into account a variety of hazard scenarios, with reasonable computational time, supporting the proper accounting of the probabilistic nature of risk in CBAs. Second, such high-resolution tools support the implementation of micro-scale damage assessment models. The latter provide information on the distribution of benefits in the investigated area, increasing the effectiveness of CBAs for policy making. Micro-scale assessments allow also a better/deeper investigation of future scenarios (i.e. risk dynamics) by means of a sensitivity analysis; on the other hand, comprehensiveness of CBAs in terms of consideration of possible direct and indirect benefits is, unfortunately, still an issue requiring improvement of the knowledge base for damage modelling. Nevertheless, in the absence of adequate damage models, neglected (avoided) damages can be considered by means of proxy variables (e.g. exposure reduction) within a more comprehensive multi-criteria analysis. Finally, the analysis put into light the complexity and the multi-disciplinary nature of flood risk management and, specifically, of CBA in disaster risk reduction; in fact, the working group included hydraulic engineers, damage analysts, urban planners and economists, the need for whom demonstrated the inappropriateness of a traditional, sectoral approach to the problem at stake.

The entire procedure proposed in this paper can be applied to other geographical contexts, at least in river basins belonging to the Po plain area, to evaluate different types of mitigation strategies, in support of the implementation of the Floods Directive. Particular attention should be paid in selecting the correct hazard, vulnerability and exposure parameters required by the Simple-INSYDE and AGRIDE-c damage models, whose further improvement and validation may guarantee their applicability in a wider number of contexts.

Acknowledgements Francesco Ballio from Politecnico di Milano and Tommaso Simonelli from the Po River District Authority are gratefully acknowledged for their fruitful suggestions and hints during the developing of the work.

Authors' contributions Conceptualization: D.M.; Design: D.M., A.R., G.M., G.P.; Hazard assessment: A.R., S.D., R.V., E.G., Damage assessment: D.M., E.G., Data Management and analysis: E.G.; Investigation of results: all; Writing — original draft: D.M., A.R., E.G., Writing - review: all.

Funding Open access funding provided by Politecnico di Milano within the CRUI-CARE Agreement. This work has been funded by Fondazione Cariplo, within the project "Flood-IMPAT + : an Integrated Meso \& micro-scale Procedure to Assess Territorial flood risk".

Data availability Data coming from the compensations forms compiled by citizens are confidential. The hydraulic model and the results of the CBA are available upon request. 


\section{Declaration}

Conflicts of Interest The authors declare no conflict of interest. The funders had no role in the design of the study; in the collection, analyses or interpretation of data; in the writing of the manuscript and in the decision to publish the results.

Open Access This article is licensed under a Creative Commons Attribution 4.0 International License, which permits use, sharing, adaptation, distribution and reproduction in any medium or format, as long as you give appropriate credit to the original author(s) and the source, provide a link to the Creative Commons licence, and indicate if changes were made. The images or other third party material in this article are included in the article's Creative Commons licence, unless indicated otherwise in a credit line to the material. If material is not included in the article's Creative Commons licence and your intended use is not permitted by statutory regulation or exceeds the permitted use, you will need to obtain permission directly from the copyright holder. To view a copy of this licence, visit http://creativecommons.org/licenses/by/4.0/.

\section{References}

AdbPo - Autorità di bacino del fiume Po (2003) - Studio di fattibilità della sistemazione idraulica dei fiumi Adda, Brembo e Serio

Brouwer R, van Ek R (2004) Integrated ecological, economic and social impact assessment of alternative flood control policies in the Netherlands. Sci Direct Ecol Econ 50:1-21

Cammerer H, Thieken AH, Lammel J (2013) Adaptability and transferability of flood loss functions in residential areas. Nat Hazards Earth Syst Sci 13(11):3063-3081. https://doi.org/10.5194/ nhess-13-3063-2013

Dazzi S, Vacondio R, Dal Palù A, Mignosa P (2018) A local time stepping algorithm for GPU-accelerated 2D shallow water models. Adv Water Resour 111:274-288

Dazzi S, Vacondio R, Mignosa P (2019) Integration of a levee breach erosion model in a GPU-accelerated 2D shallow water equations code. Water Resour Res 55(1):682-702

Dazzi S, Vacondio R, Mignosa P (2020) Internal boundary conditions for a GPU-accelerated 2D shallow water model: implementation and applications. Adv Water Resour 137:103525

Di Baldassarre G, Kreibich H, Vorogushyn S, Aerts J, Arnbjerg-Nielsen K, Barendrecht M, Bates P, Borga M, Botzen W, Bubeck P, De Marchi B, Llasat C, Mazzoleni M, Molinari D, Mondino E, Mård J, Petrucci O, Scolobig A, Viglione A, Ward PJ (2018) Hess Opinions: an interdisciplinary research agenda to explore the unintended consequences of structural flood protection. Hydrol Earth Syst Sci 22(11):5629-5637. https://doi.org/10.5194/hess-22-5629-2018

Dottori F, Figueireo R, Martina MLV, Molinari D, Scorzini AR (2016) INSYDE: a synthetic, probabilistic flood damage based on explicit cost analysis. Nat Hazard Earth Syst Sci 16(12):2577-2591

EC- European Commission, (2014) Guide to cost-benefit analysis of investment projects. Available at: Internet:http://ec.europa.eu/regional_policy/index_en.cfm

Ferrari A, Dazzi S, Vacondio R, Mignosa P (2020) Enhancing the resilience to flooding induced by levee breaches in lowland areas: a methodology based on numerical modelling. Nat Hazards Earth Syst Sci 20:59-72. https://doi.org/10.5194/nhess-20-59-2020

Galliani M, Molinari D, Ballio F (2020) Brief Communication: Simple-INSYDE, development of a new tool for flood damage evaluation from an existing synthetic model. Nat Hazards Earth Syst Sci 20:2937-2941. https://doi.org/10.5194/nhess-20-2937-2020

Gowdy J (2007) Toward an experimental foundation for benefit-cost analysis. Ecol Econ 63:649-655

Handmer J (2003) The Chimera of precision: inherent uncertainties in disaster loss assessment. Aust J Emerg Manag 18(2):88-97

IDEA (Improving Damage assessment to Enhace cost-benefit Analysis) - Deliverable D.4: Cost-benefit analysis of mitigation measures to pilot firms/infrastructure in Italy. ECHO-SUB-2014-694469. 2014

IEG - Independent Evaluation Group: World Bank, IFC, MIGA (2010) Cost benefit analysis in world bank projects, available at: https://documents.worldbank.org/en/publication/documents-reports/documentde tail/216151468335940108/cost-benefit-analysis-in-world-bank-projects

IPCC - Intergovernmental Panel on Climate Change (2014) Climate Change 2014: Impacts, Adaptation, and Vulnerability. Cambridge University Press, New York, USA 
ISTAT - Istituto Nazionale di Statistica (2011) Censimento della popolazione e delle abitazioni. Available at:https://www.istat.it/it/censimenti-permanenti/censimenti-precedenti/popolazione-e-abitazioni/popol azione-2011

Löschner L, Herrnegger M, Apperl B et al (2017) Flood risk, climate change and settlement development: a micro-scale assessment of Austrian municipalities. Reg Environ Change 17(2):311-322. https://doi. org/10.1007/s10113-016-1009-0

Mechler R (2016) Reviewing estimated of the economic efficiency of disaster risk management: opportunities and limitations of using risk-based cost-benefits analysis. Nat Hazards 81(3):2121-2147

Merz B, Kreibich H, Schwarze R, Thieken A (2010) Review article "Assessment of economic flood damage.” Nat Hazards Earth Syst Sci 10(8):1697-1724. https://doi.org/10.5194/nhess-10-1697-2010

Meyer V, Becker N, Markantonis V, Schwarze R, van den Bergh JCJM, Bouwer LM, Bubeck P, Ciavola P, Genovese E, Green C, Hallegatte S, Kreibich H, Lequeux Q, Logar I, Papyrakis E, Pfurtscheller C, Poussin J, Przyluski V, Thieken AH, Viavattene C (2013) Review article: assessing the costs of natural hazards - state of the art and knowledge gaps. Nat Hazards Earth Syst Sci 13(5):1351-1373

Molinari D, Scorzini AR (2017) On the influence of input data quality to flood damage estimation: the performance of the INSYDE Model. Water 9(9):688. https://doi.org/10.3390/w9090688

Molinari D, Scorzini AR, Gallazzi A, Ballio F (2019) AGRIDE-c, a conceptual model for the estimation of flood damage to crops: development and implementation. Nat Hazards Earth Syst Sci 19(11):25652582. https://doi.org/10.5194/nhess-19-2565-2019

Molinari D, Scorzini AR, Arrighi C, Carisi F, Castelli F, Domeneghetti A, Gallazzi A, Galliani M, Grelot F, Kellermann P, Kreibich H, Mohor GS, Mosimann M, Natho S, Richert C, Schroeter K, Thieken AH, Zischg AP, Ballio F (2020) Are flood damage models converging to reality? Lessons learnt from a blind test. Nat Hazards Earth Syst Sci 20(11):2997-3017. https://doi.org/10.5194/nhess-20-2997-2020

Natale L (2003) Delimitazione delle aree inondabili ad assegnati tempi di ritorno - Fiume Adda

Pesaro G, Mendoza MT, Minucci G, Menoni S (2018) Cost-benefit analysis for non-structural flood risk mitigation measures: Insights and lessons learnt from a real case study, in Haugen et al. (Eds) Safety and Reliability - Safe Societies in a Changing World, Taylor \& Francis Group, London, ISBN 978-0-8153-8682-7

Poelmans L, Van Rompaey A, Ntegeka V, Willems P (2011) The relative impact of climate change and urban expansion on peak flows: a case study in central Belgium. Hydrol Process 25(18):2846-2858

Rossetti S, Cella OW, Lodigiani V (2010) Studio idrologico-Idraulico del tratto di F. Adda inserito nel territorio comunale di Lodi

Shreve CM, Kelman I (2014) Does mitigation save? Reviewing cost-benefit analyses of disaster risk reduction. Int J Disaster Risk Reduct 10:213-235

Vacondio R, Dal Palù A, Mignosa P (2014) GPU-enhanced finite volume shallow water solver for fast flood simulations. Environ Model Softw 57:60-75

Vacondio R, Aureli F, Ferrari A, Mignosa P, Dal Palù A (2016) Simulation of the January 2014 flood on the Secchia River using a fast and high-resolution 2D parallel shallow-water numerical scheme. Nat Hazards 80(1):103-125

Vacondio R, Dal Palù A, Ferrari A, Mignosa P, Aureli F, Dazzi S (2017) A non-uniform efficient grid type for GPU-parallel Shallow Water Equations models. Environ Model Softw 88:119-137

Venton CC (2010) Cost benefit analysis for community based climate and disaster risk management: synthesis report London, available at: https://www.preventionweb.net/files/14851_FinalCBASynthesisRep ortAugust2010.pdf

UNISDR - United Nations International Strategy for Disaster Reduction (2009) UNISDR terminology on Disaster Risk Reduction. Switzerland, Geneva

Publisher's Note Springer Nature remains neutral with regard to jurisdictional claims in published maps and institutional affiliations. 